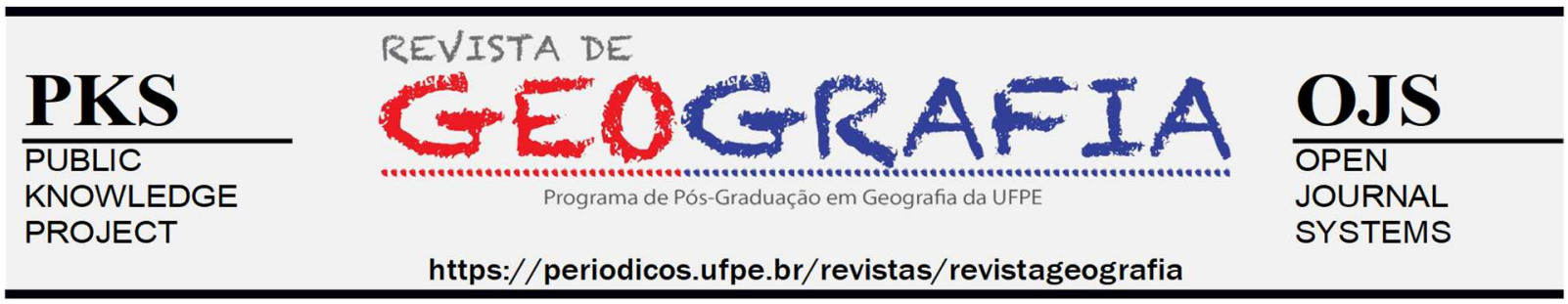

\title{
A PAISAGEM LISBOETA, EM SUA SIGNIFICAÇÃO E REPRESENTAÇÃO CONTEMPORÂNEA
}

\author{
Anelino Francisco da Silva ${ }^{1}$, Paulo César de Araújo ${ }^{2}$ \\ ${ }^{1}$ Professor Titular do Departamento de Geografia da Universidade Federal do Rio Grande do Norte, Natal/RN. \\ E-mail: anelino.francisco@ufrn.br; http://orcid.org/0000-0001-9900-3890 \\ 2 Professor Associado do Departamento de Geografia da Universidade Federal do Rio Grande do Norte, \\ Natal/RN. E-mail: pcaraujo@ufrnet.br; http://orcid.org/0000-0003-3194-9879
}

Artigo recebido em 08/07/2020 e aceito em 03/05/2021

\begin{abstract}
RESUMO
Este artigo interpreta a paisagem de Lisboa como um exercício de renovado esforço de um olhar sem preconceito, em busca de uma oculta linguagem propícia a secretos encontros nela descrita. Traz as historicidades, as relações entre espaço e sociedade, buscando compreender as formas de incorporação da paisagem cultural às práticas econômicas, políticas e espaciais, concebidas sob múltiplas abordagens, em particular as paisagens culturais, conforme suas representações e seus significados. A paisagem cultural, sob a forma de um sistema, constitui uma realidade como um todo. Sua estrutura e função são determinadas por formas integrantes. A reflexão diz respeito a uma espacialidade que compreende a Avenida da Liberdade, Praça do Rossio, Rua Augusta, Praça do Comércio e o Chiado. Nesse cenário, se apreende, em particular, a Avenida da Liberdade, que liga a Praça dos Restauradores à do Marquês de Pombal. A paisagem é performada com várias faixas e largos passeios decorados com jardins e calçada à portuguesa. A paisagem de Lisboa expressa uma cultura socioespacial, moldada conforme sua arquitetura em dimensão, pois limita e abre para o invisível; conferindo ao mundo um sentido que não é mais subordinado, por exemplo, a uma crença religiosa.
\end{abstract}

Palavras-chave: Lisboa; paisagem cultural; representação; significado.

\section{THE LISBON LANDSCAPE, IN ITS CONTEMPORARY MEANING AND REPRESENTATION}

\begin{abstract}
This article interprets the landscape of Lisbon as an exercise in renewed effort and an unprejudiced look, in search of a hidden language conducive to secret encounters of the language described in it. It brings historicities, the relations between space and society, as it is about understanding the ways of incorporating the cultural landscape into economic, political and spatial practices, conceived under multiple approaches, in particular cultural landscapes, according to their representations and meanings. The cultural landscape in the form of a system constitute a reality as a whole. Its structure and function are determined by integral forms. The reflection is provided with a spatiality comprised by Liberdade
\end{abstract}


Avenue, Rossio Square, Augusta Street, Comércio Square and Chiado. In this scenario, in particular Liberdade Avenue, which connects Restauradores Square to Marquês de Pombal Square. The landscape is performed with several lanes and wide sidewalks decorated with gardens and Portuguese pavement. The Lisbon landscape, expresses a socio-spatial culture, shaped according to an architecture in dimension. For it limits and opens to the invisible; it gives the world a sense that is no longer subordinated, for example, to a religious belief.

Keywords: Lisbon; cultural landscape; representation, meaning

\section{INTRODUÇÃOO}

A reflexão sobre a paisagem urbano-cultural de Lisboa traz as historicidades, as relações entre espaço e sociedade, por buscar compreender as formas de incorporação da paisagem cultural $^{1}$ às práticas econômicas, políticas (SCHIER, 2003), e espaciais, concebidas sob múltiplas abordagens. Trata-se de compreender as paisagens culturais, de acordo com suas representações e significados sóciopaisagísticos, o que cria a possibilidade de a paisagem estar associada à dimensão espacial da cidade.

$\mathrm{Na}$ cidade, há um mosaico heterogêneo de unidades interativas no universo da paisagem, que nos expõe a uma escala de observação. Daí pressupormos que o lidar com a paisagem como um todo, considerando as interações espaciais entre unidades culturais e naturais, cria a perspectiva de apreendê-las como expressão cultural geográfica.

A paisagem cultural pode ser compreendida como um "produto concreto e característico da interação entre determinada comunidade humana, abrangendo certas preferências e potenciais culturais, e um conjunto particular de circunstâncias naturais" (WAGNER e MIKESELL, 2003). Ela se apresenta sob a forma de um sistema. Os objetos que existem juntos na paisagem existem em inter-relação. Constituem uma realidade como um todo. Sua estrutura e sua função são determinadas por formas integrantes.

No caso específico do corredor objeto de nossa reflexão, formado pela Avenida da Liberdade, Praça do Rossio, Rua Augusta e Praça do Comércio, em Lisboa, a análise se atém

\footnotetext{
${ }^{1} \mathrm{O}$ tema das paisagens culturais coloca-se, na atualidade, como uma forma inovadora de conceber a proteção e a gestão do patrimônio cultural. Em primeiro lugar, porque permite superar a dicotomia até hoje presente na atuação dos órgãos públicos de preservação, no que diz respeito ao tratamento do patrimônio material e do imaterial, do natural e do cultural, entendendo-os como um conjunto no qual os diferentes significados se articulam num todo vivo e dinâmico.
} 
a explicitar a representação e o significado que a paisagem nele contida expõe nas leituras que ele permite construir.

\section{A LEITURA DA PAISAGEM LISBOETA EM SUA DIMENSÃO SOCIOESPACIAL}

A expressão espacial da influência humana sobre a paisagem é a forma específica de uso do solo, por meio das alterações que se fazem no espaço geográfico. A paisagem apresenta determinadas funções que podem ser associadas a processos culturais que legitimam. Do ponto de vista da percepção, a multiplicidade, a particularidade e a beleza se exprimem numa função integrada de como a imagem da paisagem é percebida. Conforme Stefan Lang e Thomas Blaschke (2009, p. 82), esses conceitos designam, por um lado, aspectos de experiências cotidianas; por outro, também características que devem ser valorizadas por critérios predefinidos objetivos e jurídicos, mas também científicos.

Uma paisagem implica um sistema integrador, como expressa OlafBastian (2001), por consequência a paisagem contribui para a formação de culturas de características locais bem como para o bem-estar do homem e para a consolidação da identidade da região.

Arranjos espaciais, ou ângulos paisagísticos, produzem impressões detectáveis da paisagem, que correspondem a percepções múltiplas. O recorte espacial Lisboa nos conduz a detecção de que paisagens transformadas podem expressar dinâmicas peculiares.

Em relação ao sujeito perceptivo, podemos aproximar-nos dele observando efeitos de diferentes cenários de paisagens. Considerar mais detalhadamente aspectos da paisagem ou, ainda, de pontos de vista psicológicos da percepção da paisagem remete-nos a uma visão de conjunto - "às ideias de concepção funcional-cognitiva" segundo Kaplan (apud Lang, Blaschke, 2009, p.82). Assim, os cenários da paisagem são preferidos especialmente quando, no indivíduo que os detecta, despertam, por um lado, familiaridade, por outro curiosidade e necessidade de nova prospecção, novo conhecimento.

Considerando a particularidade e a beleza, na ótica perceptiva podemos apreender que as paisagens lisboetas trazem em si feições, ou significados, de diferentes aspectos, que resultam do entendimento do dia a dia do conceito de paisagem. A interpretação humana leva aos atributos "belo", "encantador", "múltiplo" ou "vivificante" (LANG, BLASCHKE, 2009, p 87). 
É sob a particularidade e a beleza das paisagens lisboetas, seguindo o recorte estabelecido (Figura 1), que concebemos a deteç̧ão da representação e os limites dentro dos quais tais paisagens podem refletir o ser e o conteúdo do sentido que a encerram (HARD, 1970).

A visibilidade e a conectividade das paisagens permitem reconhecer que a realidade da paisagem objeto de nossa reflexão é reconstruída pela lógica dessa realidade expressa e que exprime atributos da forma da paisagem e da ordenação espacial.

Os cenários, ou recortes, sobre os quais aqui refletimos se entrecruzam espacialmente, visto que constituem elementos significativos expressivos da paisagem de Lisboa. Ao cenário paisagístico em referência - a Baixa - atribuímos um significado que corresponde a uma configuração espacial onde é factível e perceptiva uma tipificação de paisagem, expressa na Rua Augusta e no Arco Triunfal da Rua Augusta² , lado norte da Praça do Comércio.

Essa rua tem uma representação e um significado, no contexto paisagístico do espaço em questão, pois, além dessa contextualização, ela serve de via de circulação de pedestres, de apresentação de artistas de rua e, especialmente, é objeto de apreciação paisagística arquitetônica. A visibilidade do arranjo arquitetônico remete a um padrão: a funcionalidade, que vai do comércio de comidas e de vestuário à moradia. Na leitura linear-longitudinal observa-se, ao fundo o Arco Triunfal, que a separa da Praça do Comércio.

\footnotetext{
${ }^{2}$ O Arco Triunfal da Rua Augusta é obra do arquiteto Santos de Carvalho. Celebra a reconstrução da cidade após o terremoto.
} 
Figura 1. Recorte espacial da área estudada

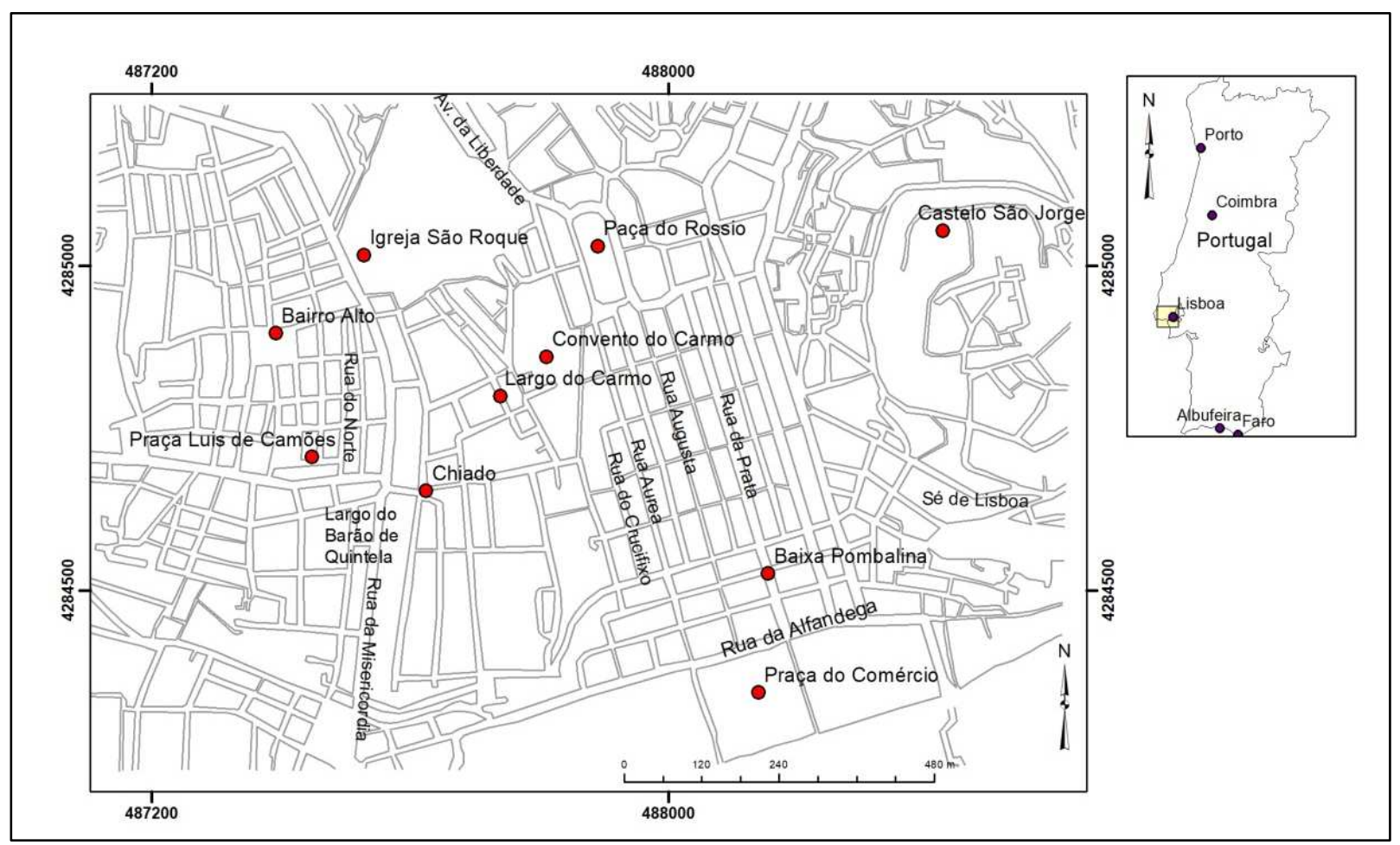

Fonte: Os autores (2020)

Essa rua tem uma representação e um significado, no contexto paisagístico do espaço em questão, pois, além dessa contextualização, ela serve de via de circulação de pedestres, de apresentação de artistas de rua e, especialmente, é objeto de apreciação paisagística arquitetônica. A visibilidade do arranjo arquitetônico remete a um padrão: a funcionalidade, que vai do comércio de comidas e de vestuário à moradia. Na leitura linear-longitudinal observa-se, ao fundo o Arco Triunfal, que a separa da Praça do Comércio.

Numa leitura ressignificada desse espaço, impõe-se a paisagem cultural, identificada na apropriação espaço cultural pelas pessoas que trafegam, quase sempre, em direção à Praça do Comércio e suas bordas. (Figura 2). 
Figura 2. Rua Augusta - liga a Praça do Rossio à do Comércio

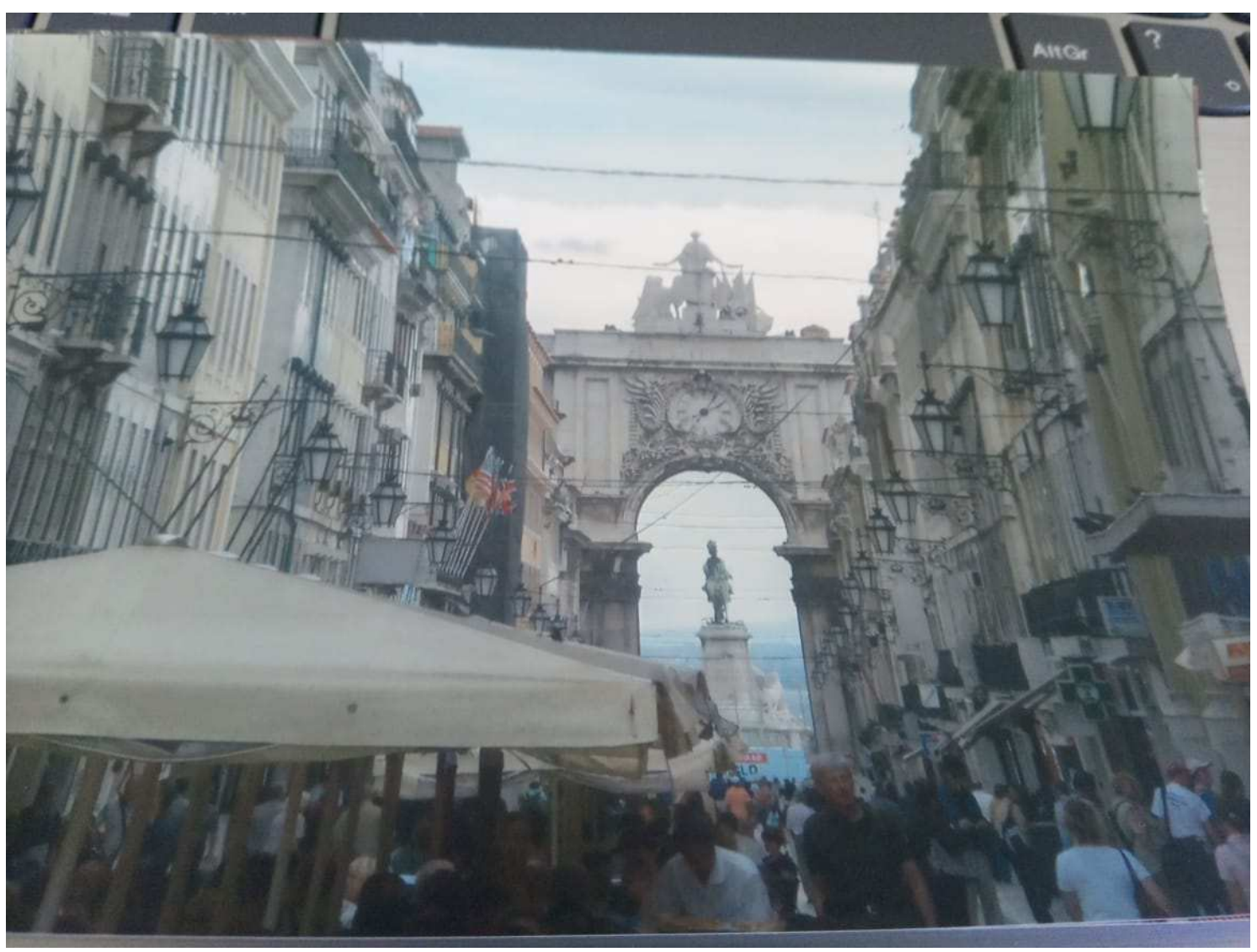

Fonte: Os autores (2020)

Sua fisionomia é formada por um conjunto de edifícios, instalados em seus lados, e abertado lado sul, no sentido do Rio Tejo. Vislumbra-se também, na borda da praça, à margem do rio, a estação fluvial Cais de Sodré, de onde saem às excursões pelo Tejo e os barcos que cruzam o rio. A relação área-borda do cenário em questão leva-nos a enveredar por trilhas que se caracterizam e se otimizam em razão do processo de ocupação espacial.

Como as paisagens transformam-se e como as paisagens culturais são criadas pelo homem por meio de "sua experiência e pelo envolvimento com o mundo que as rodeia" (ALVES, 2001, p. 68), há de se compreender, nesse tempo real de mudanças das paisagens, a criação dos valores paisagísticos associados aos espaços que resultaram de processos factuais expressos e planejados.

Se nos reportarmos à origem desse espaço, provavelmente sua estrutura arquitetônica e urbanística não representava então uma leitura espaço cultural, mas implicava uma determinação de relações espaciais harmônicas. 


\section{O ROSSIO -- CULTURA E IDENTIDADE ESPACIAL}

Que imagens simbolizam o Rossio? Os valores paisagísticos são valores socioculturais construídos em determinados contextos de tempo e de espaço e, desse modo, estão em contínua mudança e evolução. As paisagens, como processos de produção do espaço, sofrem transformações, que se traduzem em alterações substanciais na organização do território.

APraça do Rossio ${ }^{3}$, em sua estrutura paisagística, é complexa, porque, como centro nevrálgico de Lisboa, atrai pessoas de todas as índoles, credos, consumidores culturais e consumidores da gastronomia.Localiza-se na Baixa, no extremo norte da Rua Augusta, próximo a Praça dos Restauradores.

Sendo o registro da paisagem um "processo cerebral”, uma percepção que pode ser transmitida pela fala, pela escrita, pela pintura ou pela música, cada um dos agentes é produtor de espaços e também utilizador" (AMARAL, 2001, p.76). A representação é polissêmica e a figura geográfica, organizada por geogramas, destinada a convencer, é, por natureza, funcional e deve ser visivelmente persuasiva (BERQUE, 1999, p.321).

A paisagem do Rossio se expressa, visualmente, por meio do ambiente da praça, pelos teatros, pela estação ferroviária do Rossio -- de onde saem os trens para Sintra--, pela igreja e pelo aparato sociocomercial, que lhe dá uma panorâmica de contemporaneidade espacial, e a art déco representado pelo Café Nicola.

Na paisagem do Rossio, é perceptível o entrelaçamento de grupos étnicos, que têm nesse reduto um ponto de encontro. Há também, nesse espaço cultural, a contemplação de sua representação espacial, com um movimento de transeuntes que buscam se apropriar da paisagem numa admiração de devaneios dialéticos.

Seu valor cultural expõe elementos marcantes da paisagem simbolicamente destacados pela forma do espaço e do tempo. Como afirmou Viriato Soromenho-Marques (2001, p. 151152) a "filosofia da paisagem exige que aquilo que contemplamos no horizonte não seja redutível a objeto passivo, seja da técnica humana, seja da inteligência divina".

\footnotetext{
${ }^{3}$ Oficialmente, chama-se Praça Dom Pedro IV. A Praça do Rossio e sua adjacência constituem um ambiente animado da cidade e ponto de encontro de lisboetas e visitantes. Há um aparato, nos lados da praça e em seus arredores, onde são encontrados lojas, bares e restaurantes dos mais tradicionais e famosos da cidade.
} 
Ora, pensar a paisagem obriga a um exercício de atenção renovado, ao esforço de um olhar sem preconceito, de uma audição fina dos ventos do mundo, em busca de uma oculta linguagem propícia a secretos encontros (SOROMENHO-MARQUES, 2001, p. 151).

Pensar a paisagem implica também a presença de um juízo crítico sobre o poder humano de modelar e transformar. A paisagem cosmopolita do Rossio alimenta o encontrar e o repensar valores da cidade, onde o velho e o novo acentuam fatores e elementos geográficopaisagísticos.

A dinâmica cultural do Rossio se expõe pela visibilidade do Teatro Nacional Maria I, dos cafés: o Café Nicola, o Café Beira Gare, restaurantes e monumentos, como fontes. E do pedestal, no centro da praça, com a estátua de Dom Pedro IV, também chamado de Dom Pedro I, no Brasil. A Praça do Rossio, seu chão, é verdadeira obra de arte, com pedras de calcário pretas e brancas em padrão ondulante. Nela, os pombos estão sempre a sobrevoando, em busca da alimentação e de banhar-se na fonte.

\section{CARACTERÍSTICA CÊNICA E REPRESENTAÇÃO DA PAISAGEM LISBOETA}

Ver Lisboa, enquanto paisagem cultural remete-nos a sua característica cênica e sua representação, como patrimônio dos lisboetas. Em sua cartografia social, observa-se que a mobilidade das pessoas e a fisionomia arquitetônica desenham a expressão orquestrada pela sonoridade, pelo odor e pelo que representa o rio Tejo, com maestria, caracterizando a onda imagética que se produziu por meio da formatação de paisagem concebida pelos veleiros e sua representação espacial arquitetada.

É importante considerar o que Bastian fala sobre a paisagem, que ela implica um sistema integrador de componentes do meio-ambiente e sociais (BASTIAN, 2001) ${ }^{4}$. Sob tal compreensão é que refletimos acerca das manchas da paisagem, ou seja, dos elementos da paisagem indutores das reflexões.

As características concebidas na área de Baixa Pombalina, Chiado e Alfama são portadoras daquela herança (componentes do meio ambiente e sociais), assim expressando sua identidade cultural.

${ }^{4}$ Bastian, Olaf. Landscape Ecology - towards a unified discipline? LandscapeEcology, n.16, p. 757-66, 2001. \begin{tabular}{lll}
\hline Silva e Araújo, 2021 & 215
\end{tabular} 
As paisagens socioculturais contemporâneas, a assinalar expressões urbanas que pontuam a vida urbana de Lisboa, em sua dimensão mais estética e artística ou de tonalidade mais sociopolítica, remetem-nos para o esplendor e a crise do universo urbano quotidiano.

As perspectivas de reflexões, como as dimensões e os modos de representação da cidade, exprimem vestígios. Marcas e celebrações diversas assinalam essa preocupação. Mesmo quando se fala do tempo instantâneo, típico de uma cultura de consumo, as paisagens urbanas contemporâneas revelam essa preocupação de vários modos. Um desses sinais são as construções de vias rápidas e boulevards, cuja tradição remonta à ação de Haussmann na cidade de Paris, de meados do século XIX, que marcam a paisagem urbana moderna ou industrial.

O que mais caracteriza a mudança, segundo Fortuna (2015), é a "transição de um regime de tempo longo e de espaço curto, para um outro de tempo curto e de espaço longo". Essa tendência marca a paisagem urbana de hoje, carregada de passagens subterrâneas ou aéreas, viadutos, vias rápidas, ascensores, túneis e rotundas, com o intuito de facilitar os fluxos de pessoas e mercadorias.

Apreender a paisagem de Lisboa é possível considerando-se a cartografia da cidade, isto é, seus bairros, com suas distintas características, e a leitura que ela esboça. Ao lê-la, constata-se que Lisboa é uma cidade repleta de espaços verdes de variadas dimensões, com elementos presentes, ausentes, visíveis ou invisíveis. É assim que a paisagem urbana deve ser "apreciada, lembrada e contemplada", segundo Lynch (2011).

A reflexão sobre a paisagem lisboeta aqui explicitada se refere à mancha/cenário paisagístico da Baixa Pombalina. Seu interior é marcado pelo vanguardismo da época pombalina (Marquês de Pombal) e se caracteriza por "uma grelha de edifícios anti-sísmicos". Essa área central de Lisboa estende-se das margens do Rio Tejo até a Avenida da Liberdade, situando-se entre as colinas das áreas de Alfama e do Chiado. Assim, na reflexão sobre a paisagem, a variedade dos seus matizes e perspectivas, em termos muito gerais, poderá considerar-se como zona cultural, a Praça do Comércio (Terreiro do Paço), o Rossio, a Praça da Figueira (Figura 3), o Cais do Sodré, o Chiado, o Carmo, a Sé e a colina do Castelo de São Jorge. 
Nessa paisagem cultural, encontram-se centros tecnológicos de interpretação histórica, museus contemporâneos, lojas de designers famosos e uma variedade de coisas peculiares, de identidade dos lisboetas.

A paisagem da Baixa Pombalina é identitária, para os lisboetas, considerando-se o encantamento da natureza desse espaço urbano contemporâneo. Por isso é oportuno o apropriamento da interpretação e reflexão sobre a paisagem na interpretação de Teixeira Pascoaes (1993, p. 2) que afirma: "Avisto sempre, na paisagem, uma forma concreta ou revelada e outra a revelar-se vagamente".

Figura 3. Praça da Figueira

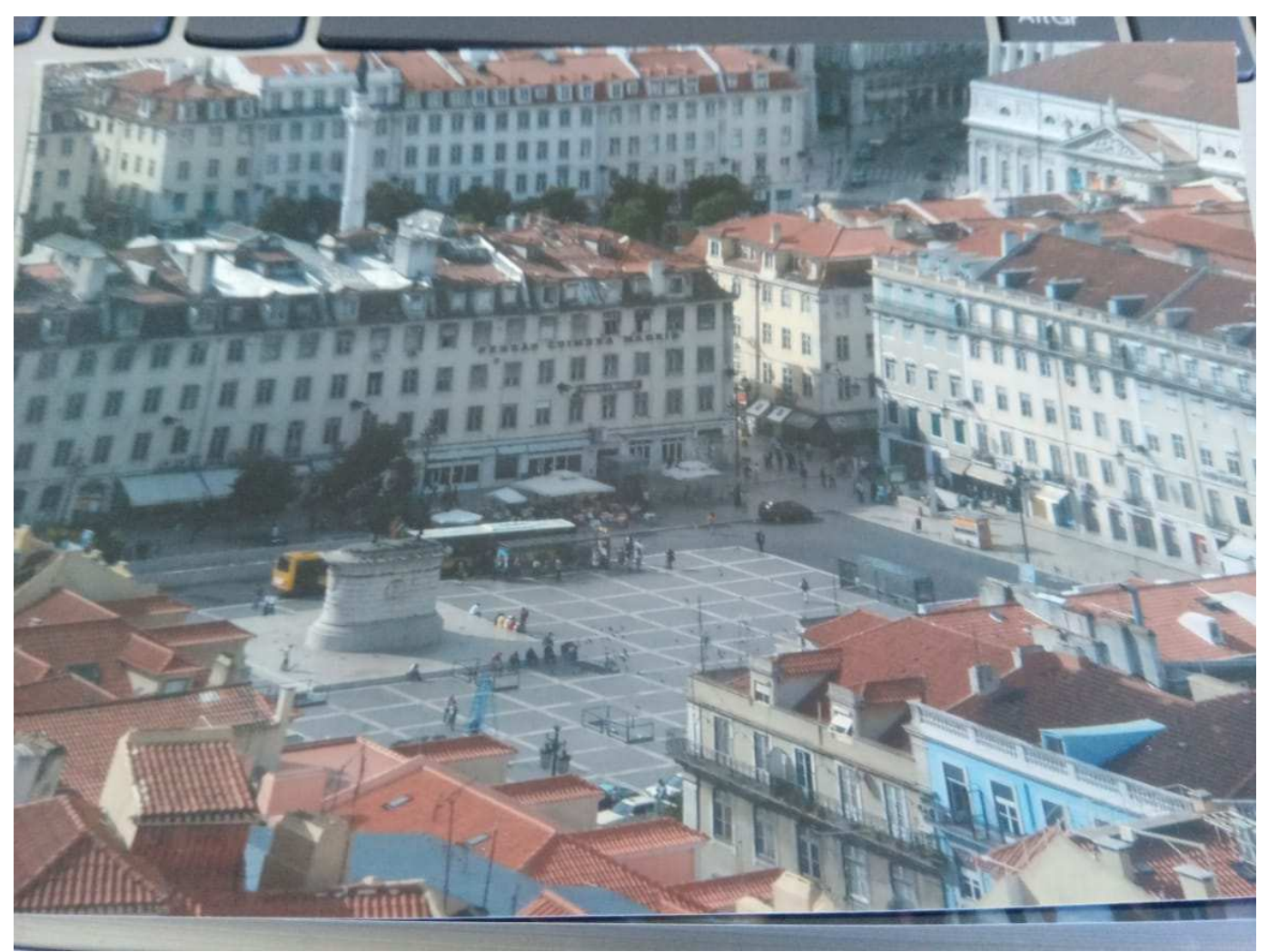

Fonte: Os autores (2020)

$\mathrm{O}$ apreender as paisagens culturais expostas nos espaços da cidade possibilita compreender, no círculo de experiências vivenciadas e da representação, a vertente perceptiva do revelar-se enquanto aspectos culturais perceptíveis e imperceptíveis. Desse modo, é oportuno entender que a "paisagem não é, em sua essência, feita para se olhar, mas a inserção de seu ser com os outros, base de seu ser social" (DARDEL, 2011, p.32). 
Como valor cultural e societal, a paisagem constitui uma realidade dinâmica. Por essa razão, ela não é passível de tipificações datadas nem de processos de cristalização: os usos alteram-se, assim como as relações dos habitantes e dos visitantes com os territórios. É fundamental saber incorporar sutilmente as mudanças, mantendo ou reforçando os valores de identidade, de memória e de uso (PNPOT, 2007). É na paisagem que se encontram os resultados das ideias e ações humanas. "Se as paisagens não são realidades objetivas, seu papel na vida dos grupos humanos é mais complexo do que geralmente se pensa. Ela desempenha o papel de suporte de mensagens e de símbolos" (CLAVAL, 2001, p. 58).

Como destaca Meinig (2002), por a paisagem ser composta pelo material e pelo imaterial, sua abstração depende da percepção e dos significados a ela atribuídos individual e coletivamente: “(...) qualquer paisagem é composta não apenas por aquilo que está à frente dos nossos olhos, mas também por aquilo que se esconde em nossas mentes (MEINIG, 2002, p. 35).

No recorte espacial aqui estudado, estão também a Avenida da Liberdade e o Chiado. Nesses cenários, se apreendem, em particular, que a Liberdade liga a Praça dos Restauradores à do Marquês de Pombal. Sua paisagem é performada com várias faixas e largos passeios decorados com jardins e calçada à portuguesa. Sua fisionomia paisagística remete-nos a sua origem de boulevard - chamado passeio público -, inicialmente murada, tendo, posteriormente sido alterada em 1830 e 1840 pelo arquiteto Malaquias Ferreira Leal), que introduziu novo arranjo de jardins e fontes, com quedas d'água e estátuas alegóricas que representam o rio Tejo e o rio Douro.

Como espaço público, fazem-se leituras diversas de sua paisagem - importante via de circulação, palco principal dos desfiles tradicionais das festas de Lisboa -, onde se executam, na noite de véspera da festividade de Santo Antônio de Lisboa, as marchas de Lisboa que competem entre si pelo título de melhor marcha, e outros itens

A paisagem da Liberdade se completa com o glamour das lojas de grife (Louis Vuitton, Prada, Dolce\&Gabbana, Carolina Herrera, MiuMiu, Armani, Gucci e Burberry, em lojas próprias, além de outras multimarcas conhecidas no mercado mundial), dos hotéis luxuosos, das fontes e esplanadas magníficas sob as árvores. Majestosa, porém dividida por faixas de trânsito que ligam a Praça dos Restauradores, a sul, à Praça do Marquês de Pombal, a norte. 
Desses elementos paisagísticos, apreende-se que é indispensável compreender as tendências refletidas no ambiente. Não se pode esquecer que as manifestações, nesse âmbito, refletem sempre fenômenos de outras amplitudes socioespaciais, as quais expressam nuanças intrínsecas que configuram transformações no tempo e no espaço. As paisagens tendem a prognosticar ações magnéticas da cidade que atrai mais gente. (SERPA, 2011, p. 102).

\section{REFLEXÕES (RE)DESENHADAS DAS PAISAGENS INCRUSTADAS NO CHIADO}

Já antes do início do século XX, o Chiado apresentava-se como cenário de eventos festivos, onde religioso e profano se ligavam. Era ponto essencial de passagem, na partida e no regresso para a igreja de São Roque, anexa ao Colégio da Companhia de Jesus, onde pairava o espírito da Contra-Reforma e os princípios definidos pelo Concílio de Trento. Aqui se celebravam os eventos mais importantes e representativos da hierarquia social e da religiosidade, com a participação da aristocracia e do povo e sempre com a presença do rei e da corte." (CALADO, 2019).

Entretanto é no século XXI que o Chiado reforça seu perfil de bairro cosmopolita, espaço de tertúlia e centro cultural. A abertura do Café no Chiado, no local da antiga Livraria Morais, por iniciativa do Centro Nacional de Cultura, tal como a dinâmica cultural instalada no Grêmio Literário, são marcos desse processo de ressurgimento de locais de fruição e sociabilidade.

A refuncionalização dos antigos Armazéns do Chiado, com atividades de hotelaria, restauração e comércio, onde se inclui um espaço dedicado ao livro e à multimídia (Livraria Fnac), em simultâneo com a reabilitação do Teatro Municipal São Luiz e do Teatro-Estúdio Mário Viegas e a reprogramação do Teatro de São Carlos e do Teatro da Trindade, contribui para uma ampla e diversificada oferta cultural. Palco de alguns eventos emblemáticos da cidade, com razão o Chiado é hoje conhecido como um importante "ponto de encontro" dos lisboetas e dos que visitam Lisboa. (CALADO 2019).

No Chiado está incrustada a paisagem cultural, a percepção do elegante e boêmio dele, destacando-se as ruas do Carmo (as ruínas da igreja de Nossa Senhora do Carmo (séc. XIV) e os "arcos em forma de ogiva") e da Garret, importante logradouro cultural. Nessa paisagem, vislumbra-se o ponto de passagem ao café A Brasileira, adiante a Praça Luís de Camões, que 
leva as pessoas a seguirem em direção de paisagens interessantes. Além disso, nesse espaço paisagem se destaca a atividade comercial, tendo-se como exemplo o Armazém do Chiado.

Nessa leitura de paisagens, o Chiado (localizado entre o Bairro Alto e a Baixa Pombalina, freguesia de Santa Maria Maior) contém paisagens emblemáticas e tradicionais da cidade de Lisboa. Seus elementos paisagísticos estão postos via espaço cultural, com diversos teatros, como o Teatro S. Luiz, o Teatro da Trindade, e o Teatro de São Carlos, único teatro de ópera em Portugal.

A paisagem desse espaço está repleta de elementos que revelam quão importantes são as marcas culturais, como a do Convento do Carmo e a do Palácio Valadares, onde está erguido o portão do Elevador de Santa Justa (construído pelo engenheiro Raoul Mesnier Du Ponsard), que liga o Largo do Carmo à Baixa Pombalina, nomeadamente à Rua do Ouro.

Nesse aparato sociocultural, há também o Museu Nacional de Arte Contemporânea, mais conhecido como Museu do Chiado, com obras a partir da segunda metade do século XIX em diante.

E, no Largo do Chiado, erguem-se duas igrejas barrocas: a italiana, Igreja do Loreto, no lado norte, e a Igreja de Nossa Senhora da Encarnação, em frente, com as paredes exteriores parcialmente decoradas com azulejos.

Também englobado na zona do Chiado, encontra-se o Largo do Carmo, com seus jacarandás. Nesse largo, resistem as ruínas do Convento do Carmo, construído no século XIV, onde está, atualmente, instalado o Museu Arqueológico do Carmo. Em frente ao convento, está o Chafariz do Carmo, datado do século .

\section{A PAISAGEM RESIDENCIAL E O BOÊMIO DO BAIRRO ALTO}

Chiado e Bairro Alto se imbricam por meio da Praça de Luís de Camões, que faz limite entre os dois. No Bairro Alto, experiencia-se sua paisagem residencial e de uso boêmio, com ruas estreitas de asfalto com paralepípedo, lisas e escorregadias, pelo uso de pessoas residentes, visitantes e turistas subindo e descendo e também por estarem grafitadas e, pelos varais de roupas estendidas, ao balanço do vento. A paisagem parece completar-se com as excelentes diversões noturnas, nas ruas da Rosa, do Diário de Notícias e do Atalaia. E as "tascas", pequenos restaurantes, nos quais se consomem pratos maravilhosos. 
$\mathrm{Na}$ composição de paisagens do Bairro Alto, observa-se também o bonde 28, a percorrer ruas estreitas, permitindo que lisboetas e turistas façam trajetos culturais. Nela, o elevador de Santa Justa se impõe na paisagem e ainda serve de mirador para que se observem os telhados das casas. Outro elemento espacial dessa paisagem é o elevador da Glória, na Praça dos Restauradores. Ele sobe e desce entre os Restauradores e o Bairro Alto. São 275 metros de calçada, com uma inclinação de cerca de $18 \%$, que demora cerca de um minuto e meio a dois minutos para subir ou descer. Ou, como exibido e cantado na Rádio Macau: "Desde este lugar sem história/Até um lugar na história/ Vão apenas dois minutos/No elevador da glória 5". Na parte superior, que já é o Bairro Alto, há o miradouro de São Pedro de Alcântara e a Igreja de São Roque.

\section{CONSIDERAÇÕES FINAIS}

Composta por várias realidades e dinâmicas distintas de paisagens, Lisboa é uma cidade metropolitana, que compõe um espaço diverso, dotado de uma enorme complexidade. A forte expansão urbana, formando um tecido consolidado pela transformação do espaço/território, nem sempre teve uma estrutura coesa e qualificada em termos de paisagem urbana.

Uma diversidade de realidades hoje forma à paisagem da cidade -- cidade estática (quando se reflete sobre os imóveis) e dinâmica, ao mesmo tempo, quanto a sua plasticidade. Basta observar a paisagem de ruas e avenidas, para se perceber que o surgimento de detalhes é incessante. É a legibilidade, de que trata Lynch (2011), a qual é percebida, como um modelo de símbolos identificáveis na cidade visível objeto dessa reflexão.

Desvendamos as dinâmicas dessa paisagem, considerando uma forma especializada de representação e significado desse cenário paisagístico que é Lisboa. Nesse contexto, os valores criados na forja do espaço geográfico amalgamam-se à paisagem produzida, caso das ruas e avenidas enquanto expressão material da história social e urbana desse espaço.

Não partimos, nesta abordagem, da paisagem em sentido físico imediato, mas dos elementos que representam a política do espaço específico, da apreensão que a paisagem

\footnotetext{
${ }^{5}$ Texto da letra: O elevador da Glória. Divulgado na/em Rádio Macau. Sites:www.cifraclub.com.br/radiomacau/14124989/letra/imprimir.html e https://www.musicmatch.com.pt.br/letras/radio-macau/elevador-daGloria. 
estabelece e da memória social. Nesse sentido, as reflexões que realizamos aliam-se à representação e ao significado de uma estética enquanto traço saliente da identidade local, o que possibilita pensar o significado dos elementos que legitimam a representação do espaçopaisagem.

Logo, as leituras procuram deter-se em paisagens como a Praça do Rossio, a Rua Augusta, a Praça do Comércio e a da Avenida da Liberdade. Apreendemos que os elementos estruturantes dessas paisagens, enquanto logradouros, correspondem à história do espaço, que guarda e representa o estado da arte do fazer e do refazer de significantes e de significados desse espaço vivido e experienciado pelas pessoas que vão até lá descobrir o visível e o invisível desse conjunto de paisagens lisboeta.

Buscamos explicitar que Lisboa, enquanto espaço-paisagem, significa espaço cultural, que se contempla em sua representação espacial e se concretiza, especialmente, em razão da dinâmica das pessoas que transitam por tais espaços-paisagens, lendo-os, admirando-os, numa busca de se apropriarem sem devaneios sobre a paisagem. Porque a fisionomia arquitetônica desenha e exprime uma orquestração que se expressa pela sonoridade, pelo odor e pelo que representa o Tejo, maestria.

Em sua representação e significado, a paisagem esboça uma construção estética - que se exemplifica em cultura material e imaterial sob base espacial. Em suma, diz respeito a vínculos sociais, trânsito de coisas, significados e narrativas, que se preservam pela possibilidade da produção e da reprodução das paisagens que compõem o espaço. A paisagem tende a reproduzir dinâmicas especializadas de culturas e vivências.

Assim, a paisagem produzida pelo trabalho do homem é concebida e apropriada pelas pessoas como bens visíveis, que, por sua representação e seu significado, subsidiam a realidade dinâmica espacial dessa paisagem, visto que a construção do sublime revela a forma de representação, a do prazer visual e da beleza suave que a faz ser significativa.

Por essa lógica, as paisagens, enquanto realidades são sensações transformadoras. $\mathrm{Ou}$ seja, há uma relação entre a paisagem e quem a lê, que pode ser explorada de diversas formas, em que é possível a pessoa colocar-se, também dentro desse lugar ou nas bordas. Dada essa aproximação, esse mecanismo perceptivo, curioso e inventivo faz surgir um olhar reflexivo renovador. 
A paisagem de Lisboa, considerando-se o recorte estabelecido, expressa uma cultura socioespacial, moldada de acordo com uma arquitetura em dimensão. Ela abre-se para o invisível; confere ao mundo um sentido que não é mais subordinado, por exemplo, a uma crença religiosa.

Desse modo, a construção da paisagem lisboeta, objeto de nossa reflexão, representa o produto de uma experiência individual, sensorial e suscetível de uma elaboração estética singular, expressando experiência sensível para objetivar o espaço-paisagem sob a forma de uma extensão não homogênea, mas explícita a reflexão atemporal.

\section{REFERÊNCIAS}

AMARAL, I. Acerca de "Paisagem": apontamentos para um debate. Finisterra, v.36, n. 72, p. 75-81. 2001.

ALVES, T. Paisagem - em busca do lugar perdido. Finisterra, v. 36, n.72, p. 67-74, 2001.

BASTIAN, O. Landscape ecology: towards a unifield discipline? LandscapeEcology, n. 16, p. 757-66, 2001.

BERQUE, A. Géogramaspour une ontology de faitsgéographiques. L'EspaceGéographique, n.4, p.321, 1999.

CALADO, M. Um bairro com história. Lisboa: Centro Nacional de Cultura, 2019.

CLAVAL, P. O Papel da Nova Geografia Cultural na Compreensão da Ação Humana. In: CORRÊA, R. L.; ROSENDAHL, Z. (Orgs.). Matrizes da Geografia Cultural. Rio de Janeiro: EDUERJ, 2001.

DARDEL, E. O homem e a terra: natureza da realidade geográfica. São Paulo: Perspectiva, 2011.

FORTUNA, C. A paisagem da ruína urbana. CesContexto, n.12, Coimbra, 2015. Site: https://www.ces.uc.pt/publicaçoes/contexto/ficheiro/cescontexto_debates. Consultado: 22/05/2020.

HARD, G. D.; "Landschaft" der Sprache und die "Landschaft" der Geographen. In: C. TROLL, (Ed.). ColloqiumGeographicum, n. 11, Bonn, 1970.

SOROMENHO-MARQUES, V. Pensar a paisagem. Da aventura interior ao campo da História. Finisterra, v. 36, n. 72, 2001, p. 149-156.

LANG, S.; BLASCHKE, T. Análise da paisagem com sig. São Paulo: Oficina de Textos, 2009.

LYNCH, K. A imagem da cidade. Lisboa: Edições 70, Lda., 2011. 
MEINIG, D. W. O olho que observa: dez visões sobre a mesma cena. Espaço e cultura, UERJ, n. 13, p. 35-46, jan./jun. 2002.

PASCOAES, T. O homem universal e outros escritos. Lisboa: Assírio \& Alvim, 1993.

PNPOT - Programa Nacional de Ordenamento do território. Lisboa: Diário da República Eletrônico, 2007. Site: https://pmpot.dgterritorio.pt/pnpot.

RÁDIO MACAU. O Elevador da Glória. Divulgado na/em Rádio Macau. Sites:www.cifraclub.com.br/radio-macau/14124989/letra/imprimir.html https://www.musicmatch.com.pt.br/letras/radio-macau/elevador-da-Gloria.

SERPA, L. A cidade e as estrelas: fragmentos de paisagem. Finisterra, v. 36, n.72, 2011, p.101-104.

SCHIER, R. A. Trajetórias do conceito de paisagem na Geografia. Revista RA'EGA, Curitiba, n. 7, p. 79-85, Editora UFPR, 2003.

WAGNER, P. L.; e MIKESEL, M. W. Os Temas da Geografia Cultural. In.: CORRÊA, R. L.; ROSENDAHL, Z. (Org). Introdução à Geografia Cultural. Rio de Janeiro: Bertrand Brasil, 2003. 